\title{
Retraction Note: Improved Sensitivity of Spin Echo and Parallel Acquisitions Using SENSE Compared to Gradient Echo Sequences in fMRI
}

\author{
Sanaa El Mrini • Mohammed Hamri
}

Published online: 6 January 2013

(C) Springer Science+Business Media New York 2013

Retraction to: Sens Imaging (2012) 13:27-35

DOI 10.1007/s11220-011-0068-z

This article has been retracted due to plagiarism of text and data from the previously published article titled "Ultrafast bold fMRI using single-shot spin-echo echo planar imaging" Journal of Medical Physics, Vol. 34, No. 1, (2009) 40-45.

The online version of the original article can be found under doi:10.1007/s11220-011-0068-z.

S. El. Mrini $(\square) \cdot$ M. Hamri

Department of Physics, Faculty of Sciences, Electronic and Signal Processing Laboratory,

Rabat, Morocco

e-mail: selmrini@yahoo.com 